\title{
High Efficiency Power Converter for a Doubly-fed SOEC/SOFC System
}

\author{
Tomas Manez, Kevin; Anthon, Alexander; Zhang, Zhe
}

Published in:

Proceedings of 2016 IEEE Applied Power Electronics Conference and Exposition

Link to article, DOI:

10.1109/APEC.2016.7468026

Publication date:

2016

Document Version

Peer reviewed version

Link back to DTU Orbit

Citation (APA):

Tomas Manez, K., Anthon, A., \& Zhang, Z. (2016). High Efficiency Power Converter for a Doubly-fed SOEC/SOFC System. In Proceedings of 2016 IEEE Applied Power Electronics Conference and Exposition (pp. 1235 - 1242). IEEE. https://doi.org/10.1109/APEC.2016.7468026

\section{General rights}

Copyright and moral rights for the publications made accessible in the public portal are retained by the authors and/or other copyright owners and it is a condition of accessing publications that users recognise and abide by the legal requirements associated with these rights.

- Users may download and print one copy of any publication from the public portal for the purpose of private study or research.

- You may not further distribute the material or use it for any profit-making activity or commercial gain

- You may freely distribute the URL identifying the publication in the public portal 


\section{High Efficiency Power Converter for a Doubly-fed SOEC/SOFC System}

\author{
Kevin Tomas-Manez \\ Technical University of Denmark \\ Department of Electrical Engineering \\ Email: ktma@elektro.dtu.dk
}

\author{
Alexander Anthon \\ Technical University of Denmark \\ Department of Electrical Engineering \\ Email: jant@elektro.dtu.dk
}

\author{
Zhe Zhang \\ Technical University of Denmark \\ Department of Electrical Engineering \\ Email: zz@elektro.dtu.dk
}

\begin{abstract}
Regenerative fuel cells (RFC) have become an attractive technology for energy storage systems due to their high energy density and lower end-of-life disposal concerns. However, high efficiency design of power conditioning unit (PCU) for RFC becomes challenging due to their asymmetrical currentpower characteristics that are dependent on the operation mode (energy storage / energy supply). This paper proposes a new PCU architecture for grid-tie RFC with which the RFC's asymmetrical characteristic becomes less critical and thus a much more symmetrical power rating of the dc-dc converter for both operating modes is possible. This paper discusses the design considerations for this novel PCU, and verifies its operation principle with Matlab/Simulink simulations. Experimental results on a tailored dc-dc converter confirm the design simplifications for high efficiency operation along the entire power operating range of the RFC as well as the utilization of the same control strategy design for the two RFC operating modes.
\end{abstract}

Keywords-Bidirectional fuel cells, power conditioning, Interleaved boost converter, renewable energies, grid tie

\section{INTRODUCTION}

Over the last years renewable energies have experienced a strong development to become alternatives for conventional energy resources, among others due to the global awareness on limited fossil fuel resources and a widespread sensibility towards the environmental impacts. However, large scale integration of renewable energy sources present an important drawback because of their highly irregular and mostly unpredictable production [1], which causes high dynamics on the grid infrastructure and thus, electrical grid reliability is lowered. Large scale energy storage systems are therefore a potential solution to improve grid system reliability and stability when supplied by renewable energy sources [2]. With the utilization of information technologies to the grid system, consumers' behavior can become much more predictable, and therefore contribute to a better load regulation and an increased grid reliability [1]. The combination of renewable energy sources including energy storage systems and information technology systems can establish an equilibrium between energy production and demand, because surplus energy from renewable energy sources can be stored for later use to support the grid demands when necessary [3].

Regenerative or bidirectional fuel cells (RFC) could be an attractive technology for such large scale energy storage systems by means of hydrogen storage. Their particular benefits over traditional batteries are their high energy density of the fuel and their lower environmental disposal concerns [4]. In
[5] an energy storage system based on RFC which couples the electricity grid with the natural gas grid is presented showing the potential of RFC for large scale energy storage.

Grid-tie energy storage systems based on RFC require power converter units to couple the grid with the RFC, to accommodate voltage levels and to regulate the system power flow. For traditional grid-tie fuel cell systems (not RFC), high efficiency PCU ranging from $96.8 \%$ to $98 \%$ have been demonstrated [6]. However, RFCs present a very asymmetrical current-power characteristic depending on the operating mode (i.e. energy storage or energy supply), leading to wide power rating spans with which the power conditioning unit (PCU) has to operate at high efficiency.

Different approaches to improve system performance and efficiency have been addressed. For instance, it has been verified in [7] that the efficiency of bidirectional dc-dc converters for grid-tie RFC systems can be greatly improved with the utilization of wide bandgap semiconductors such as $\mathrm{SiC}$ MOSFETs. Another way towards increasing efficiency is to reduce the switching energies of power devices in the RFC bidirectional dc-dc converters by means of soft switching as shown in [8]. Research on magnetics optimization based on planar magnetics can further increase both efficiency and power density [9]. Other investigations aim to compensate the slow dynamics of RFC by the inclusion of auxiliary sources. For instance, in [10] a dc-dc converter for FCs with an additional battery-based energy storage and a bidirectional dc-dc converter has proven to successfully support rapid load demand, and in [16] a grid-tie multiple port converter for fuel cells with super-capacitors as an auxiliary source has been proven to clearly increase the dynamic response compared to systems without auxiliary energy storage element.

Research performed to date is based on traditional PCU architectures for energy storage systems, as the one shown in Fig. 3. However, they are limited to the power rating symmetry characteristic of the PCU itself. Power symmetry implies that the power rating of the system is equal regardless the power flow direction. Considering the asymmetrical and wide power range of RFC, the design of high efficiency PCU for the entire operating area becomes very challenging. Furthermore, due to the power asymmetry of RFC, cooling effort for the PCU can be oversized depending on the operation mode, which greatly challenges high power density design. Due to the aforementioned drawbacks with the RFC systems, this paper presents a novel PCU architecture aiming for a much more symmetrical power rating of the dc-dc converter in both 
operation modes in order to simplify the high efficiency converter design. Design considerations are discussed, principle operation modes verified by simulations and experimentally confirmed on a $5 \mathrm{~kW}$ interleaved boost converter

\section{BIDIRECTIONAL SOEC/SOFC TECHNOLOGY}

Solid oxide electrolyzer cells/fuel cells (SOEC/-SOFC) are a kind of fuel cell technology which uses hydrogen as a fuel and takes advantage of the released energy during the reaction of hydrogen and oxygen to produce electricity. It has been proven that solid oxide cells (SOCs) have the capability to operate in bidirectional mode [11], also referred as regenerative mode. When hydrogen is used a fuel, reaction of hydrogen and oxygen is produced and an amount of energy is released generating electricity when connected to a load (SOFC operation). On the other hand, when current is forced to flow through the SOCs the electrolysis of water is produced and hydrogen is generated (SOEC operation).

Design and system specifications of a grid-tie power conditioning units for SOEC/SOFC systems are defined according to the current-voltage (I-V) characteristics of the SOEC/SOFC system, which is set by the number of stacked cells. However, I-V characteristics of SOEC/SOFC are highly dependent on operating temperature, fuel, pressure and degradation as explained in [12], [13]. This dependency must be considered in mature prototyping stages for long-term operation, specially the degradation ratio since it can strongly degrade the operating voltage ratings [12], [13]. The I-V characteristic for a single SOEC/SOFC provided by SOCs manufacturers is shown in Fig. 1, which will be the starting point of the PCU design.

As shown in the I-V curve from Fig. 1, SOCs operate at very low voltage and high currents, and for that reason it is necessary to stack many cells in series. Due to the immaturity of SOEC/SOFC technology, currently there are still mechanical limitations to obtain high power SOEC/SOFC systems, among others due to the maximum number of stackable cells, current density limitations, operating temperature, etc. Currently, the maximum current capability in SOEC mode is up to $60 \mathrm{~A}$ and up to $30 \mathrm{~A}$ in SOFC mode.

For the proposed system design in this work, fours stacks in series with 75 cells per stack has been chosen in agreement with SOCs manufacturers. Fig. 2a shows the I-V characteristics and Fig. $2 b$ shows the current-power (I-P) characteristics for the SOEC/SOFC stacks system, which has been extrapolated from the I-V curve of a single cell Fig. 1. From the I-P curve in Fig. 2b, it can be seen that the power rating in SOFC mode is lower than in SOEC mode, which is due to the variation of the internal resistance and current direction [11]. This results in a very asymmetrical I-P characteristic, which leads to a wide operating power range for the PCU and thus, high efficiency design for the whole power range becomes challenging.

\section{GRID-TIE POWER CONDITIONING UNIT FOR SOEC/SOFC SYSTEMS}

\section{A. Traditional PCU architecture for SOEC/SOFC systems}

Several power conditioning topologies can be used to realize SOEC/SOFC systems, and may differ depending on the particular application, system requirements and stacks structure

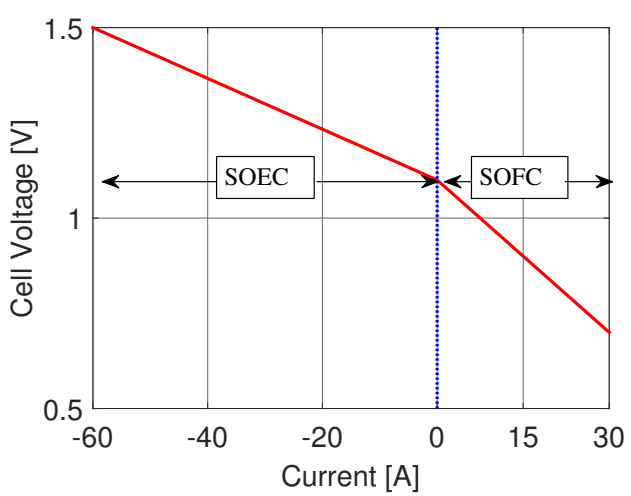

Fig. 1. Current-voltage characteristics of a single Solid Oxide Electrolyzer/Fuel Cell

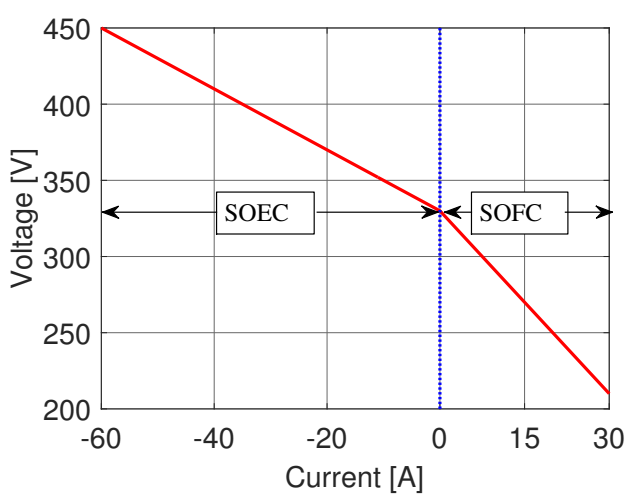

(a) Current-voltage characteristics.

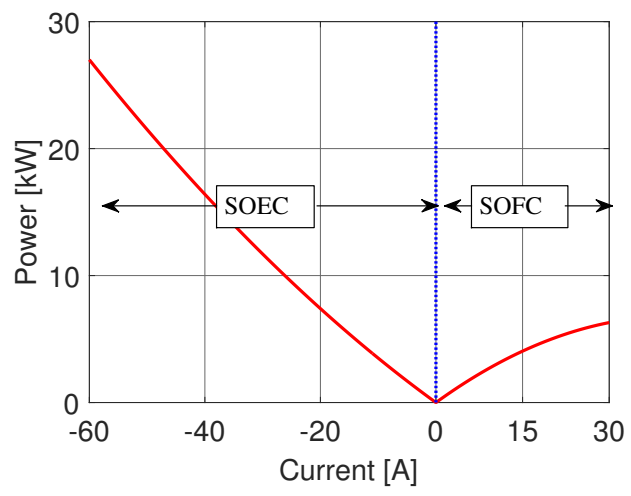

(b) Current-power characteristics.

Fig. 2. SOEC/SOFC stacks composed by 4 stacks in series with 75 cells/stack

[14]. However, the simplified architecture from Fig. 3 can be defined as a basis. System configuration is based on the parallel connection of an ac-dc converter, a dc-dc converter and the SOEC/SOFC stacks. Bidirectional power flow of the power converter units is required to allow the RFCs to operate in both modes. In particular, power flows from the grid to the SOCs when operating in SOEC mode (energy storage) and from the SOCs to the grid when operating in SOFC mode (energy generation). The dc-dc converter regulates the SOCs power flow and sets the required voltage level for the dc-link of the inverter. 
TABLE I. TRADITIONAL PCU ARCHITECTURE: SOEC/SOFC AND DC-DC CONVERTER SPECIFICATIONS

\begin{tabular}{lccc}
\hline \hline Specification & SOEC & SOFC & dc-dc converter \\
\hline Voltage [V] & $330-450$ & $210-330$ & $210-450$ \\
Current [A] & $0-60$ & $0-30$ & $0-60$ \\
Power rating [W] & 27000 & 6300 & 27000 \\
Power flow & from the grid & to the grid & bidirectional \\
\hline
\end{tabular}

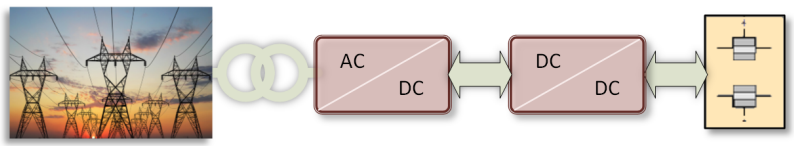

Fig. 3. Traditional PCU architecture for SOEC/SOFC systems.

According to the SOEC/SOFC stacks characteristics from Fig. 2, the system specifications for the dc-dc converter and the SOEC/SOFC stacks using the traditional PCU architecture are specified in Table I. With the traditional architecture from Fig. 3, a $27 \mathrm{~kW}$ power rated dc-dc converter would be required to cover the whole power range in both operation modes. This clearly leads to an oversized dc-dc power converter when operating in SOFC mode, which only requires a $6.3 \mathrm{~kW}$ rated system. Therefore, a different PCU architecture that counteracts the SOEC/SOFC power asymmetry would greatly simplify the converter design.

\section{B. Novel doubly-fed SOEC/SOFC system}

The novel PCU architecture presented in this work aims to achieve a much more symmetrical power operating range of dc-dc converter. The architecture is based on a dynamic PCU which connection varies according to the operation mode by the utilization of two single pole double through (SPDT) relays as subsequently explained. The proposed PCU architecture for both operation modes is shown in Fig. 4.

Under SOFC mode, shown in Fig. 4a, SOC stacks are connected in parallel to the dc-dc converter, which is the same scenario as with the traditional PCU architecture. Power is transferred from the SOCs to the output of the dc-dc converter $P_{\text {out }}$ through the dc-dc converter. Therefore the power rating of the dc-dc converter $P_{c o n v}$ is equal to the power generated by the SOFCs $P_{s o f c}$, and the dc-dc converter electrical characteristics are defined as in equations 1,2 and 3.

$$
\begin{gathered}
V_{\text {conv }(\operatorname{sofc})}=V_{\text {sofc }} \\
I_{\text {conv }(\operatorname{sofc})}=I_{\text {sof } c} \\
P_{\text {conv }(\operatorname{sofc})=P_{\text {soc }}}=V_{\text {sofc }} \cdot I_{\text {sofc }}
\end{gathered}
$$

Under SOEC mode, shown in Fig. 4b, SOC stacks are connected in series with the dc-dc converter, and these two are then connected in parallel with the ac-dc converter. Energy required for the electrolysis of water and hydrogen generation is supplied from the grid through the ac-dc converter. For this operating mode the power rating of the dc-dc converter $P_{c o n v}$ is the power difference between the output power of the dcac converter $P_{i n v}$ and the power consumed by the SOECs $P_{\text {soec }}$. The electrical characteristics of the dc-dc converter are expressed with equations 4,5 and 6 . From these equations, it can be inferred that in this scenario the power rating of the dc-dc converter will be reduced compared to the traditional PCU architecture. This is illustrated in the following design example.

$$
\begin{gathered}
V_{\text {conv }(\text { soec })}=V_{\text {inv }}-V_{\text {soec }} \\
I_{\text {conv },(\text { soec })}=-I_{\text {soec }} \\
P_{\text {conv }(\text { soec })}=P_{\text {inv }}-P_{\text {soec }}=V_{\text {conv }(\text { soec })} \cdot I_{\text {soec }}
\end{gathered}
$$

A 3-phase grid with $V_{\text {line }}=230 \mathrm{~V}$ is considered. Then the voltage at the output of the ac-dc converter is calculated with equation 7 as shown in [15].

$$
V_{\text {inv }}=\sqrt{2} \cdot \sqrt{3} \cdot V_{\text {line }} \approx 560 \mathrm{~V}
$$

According to the SOEC/SOFC stacks characteristics from Fig. 2, system specifications for the dc-dc converter and the SOEC/SOFC stacks using the proposed PCU architecture can be redefined using equations 1-6 and with the specifications from Table II. Calculations show that using a dc-dc converter rated at $6.6 \mathrm{~kW}$, a $27 \mathrm{~kW}-\mathrm{SOEC} / 6.3 \mathrm{~kW}-\mathrm{SOFC}$ system can be realized using the proposed PCU architecture. In other words, in SOFC mode the dc-dc converter maximum power is $P_{\text {conv }(\text { sofc })}=6.3 \mathrm{~kW}$ while in SOEC mode maximum power is $P_{\text {conv }(\text { soec })}=6.3 \mathrm{~kW}$, resulting not only in a much more symmetrical dc-dc converter I-P characteristic, but also clearly a four times lower rated power system and thus a reduced cooling effort.

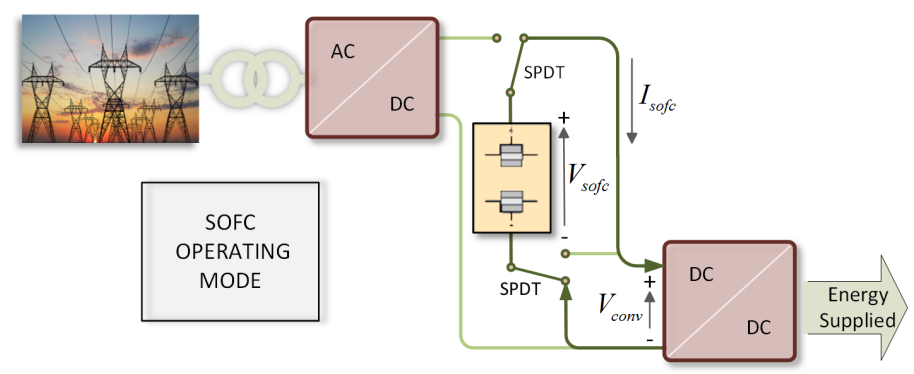

(a) SOFC mode
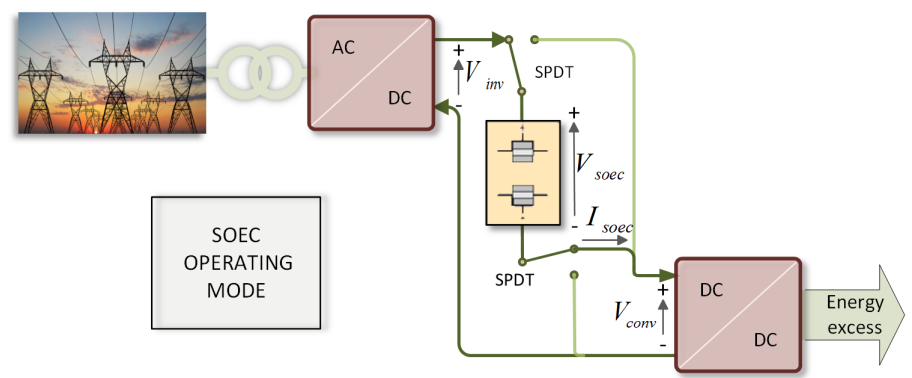

(b) SOEC mode

Fig. 4. Novel doubly-fed power conditioning architecture for SOEC/SOFC.

TABLE II. NOVEL PCU ARCHITECTURE: SOEC/SOFC AND DC-DC CONVERTER SPECIFICATIONS

\begin{tabular}{lccc}
\hline \hline Specification & SOEC & SOFC & dc-dc converter \\
\hline Voltage [V] & $330-450$ & $210-330$ & $110-330$ \\
Current [A] & $0-60$ & $0-30$ & $0-60$ \\
Power rating [W] & 27000 & 6300 & 6600 \\
Power flow & from the grid & to the grid & unidirectional \\
\hline \hline
\end{tabular}




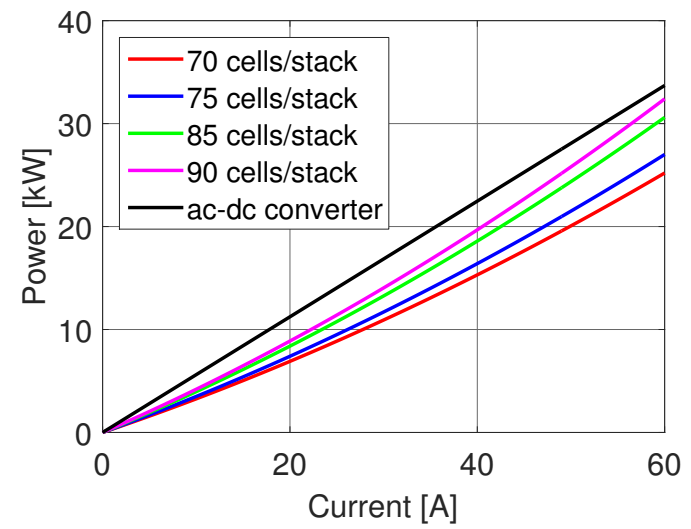

(a) SOEC/SOFC and ac-dc converter

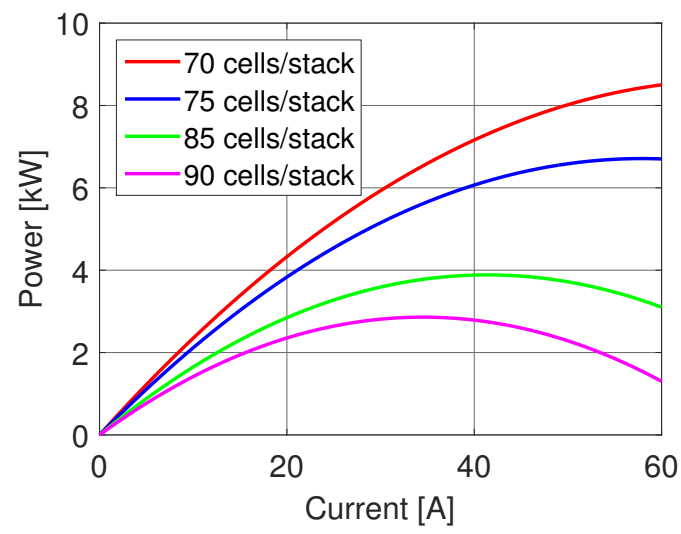

(b) dc-dc converter

Fig. 5. Current-power characteristics for different number of cells per stack with four stacks in series.

The proposed system is subsequently analyzed when operating under SOEC mode with different number of SOEC/SOFC cells by calculating the dc-dc converter specifications as previously shown. Fig. 5a shows the I-P characteristics of the SOEC/SOFC stacks and Fig. 5b shows the I-P characteristics for the dc-dc converter. Fig. 5 shows that by increasing the number of cells the power consumed by the SOEC stacks increases. Since the voltage across the SOEC stacks moves towards the inverter voltage with an increasing number of cells, the voltage at the input of the dc-dc converter decreases. This causes a significant reduction of the power rating of the dc-dc converter.

In order to describe the circuit operation in more detail, simulations of the entire PCU including a closed-loop SOEC/SOFC current control have been performed with a full bridge rectifier connected to the 3-phase grid and a boost dc-dc converter. Two ideal SPDT relays are used to switch from one operating mode to another, which occurs at very low frequencies because the operating mode is related to the grid power excess and power demand rather than conventional PWM mode of the dc-dc converter itself. Simulations are performed according to the specifications from Table II. Fig. 6a shows the current through the SOEC/SOFC system $I_{\text {conv }}$, whereas Fig. $6 \mathrm{~b}$ shows the inverter voltage $V_{i n v}$, the voltage across the SOEC/SOFC stacks $V_{\text {soec }} / V_{\text {sofc }}$ and the input voltage of the dc-dc converter $V_{\text {conv }}$. Fig. 6c shows the inverter

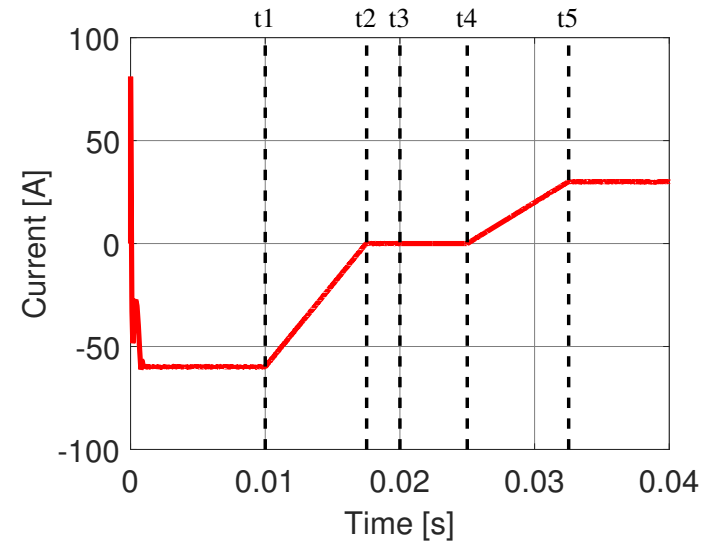

(a) Current through the SOEC/SOFC stacks $((+)$ for SOEC and (-) for SOFC)

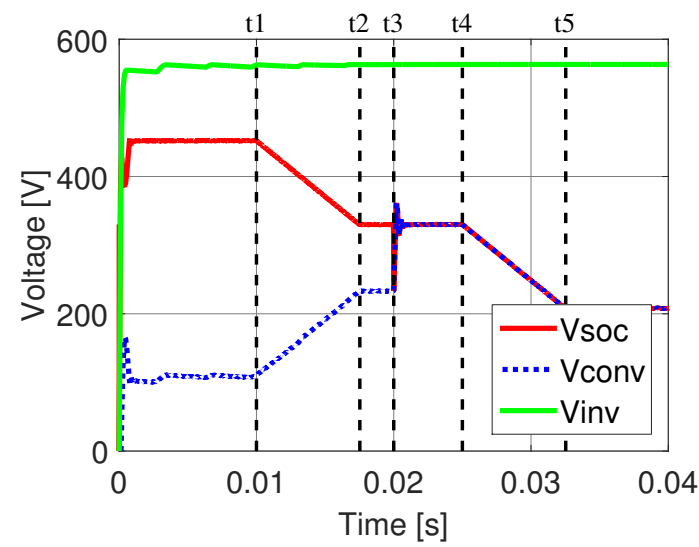

(b) Voltage at the rectifier output, SOCs and input of dc-dc converter

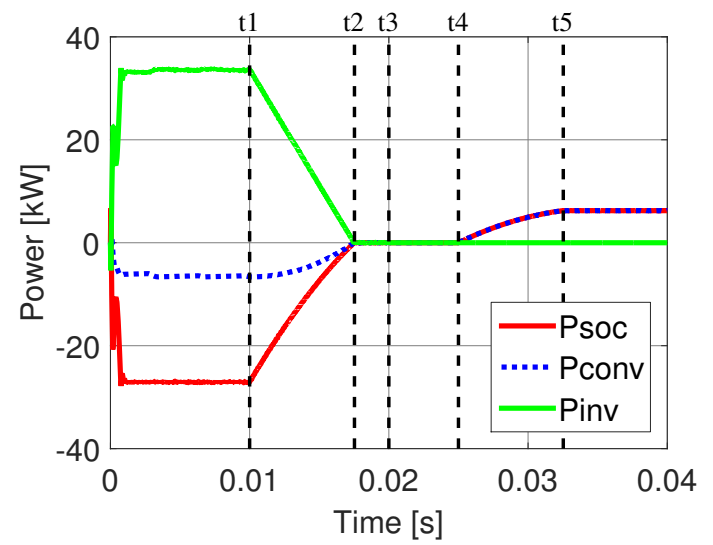

(c) Power at the rectifier output, SOCs and dc-dc converter input

Fig. 6. Simulation results

power $P_{\text {inv }}$, the power of the SOEC/SOFC stacks $P_{\text {soec }} / P_{\text {sofc }}$ and the power of the dc-dc converter $P_{\text {conv }}$.

Step 1 (before $t_{1}$ ): System is in steady state, operating in SOEC mode, as depicted in Fig. 4b. Current reference is regulated to the maximum SOEC current capability $I_{\text {soec, } \max }=$ $-60 \mathrm{~A}$. The input voltage of the dc-dc converter $V_{\text {conv }}$ is the difference between inverter voltage and SOEC stacks voltage as expressed by equation 4 , and thus $P_{\text {conv }}$ corresponds to 


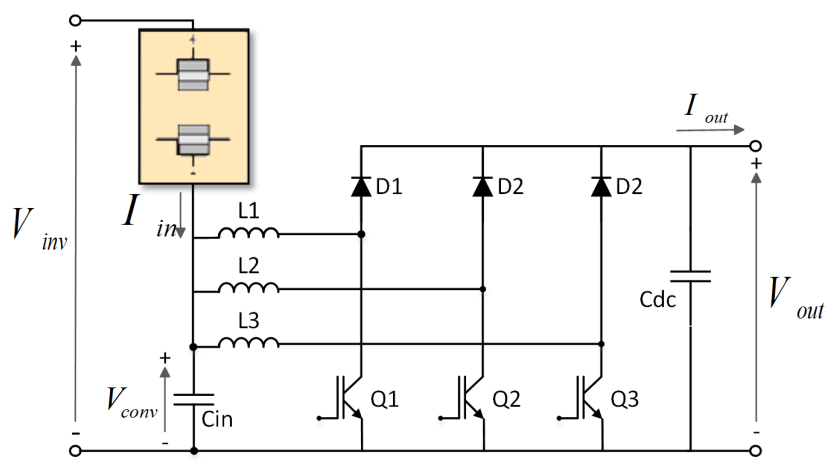

Fig. 7. Three stages interleaved boost converter schematic operating in SOEC mode.

$P_{\text {inv }}-P_{\text {soec }}$ (Eq. 6). Note that $P_{\text {soec }}$ is negative in Fig. 6c, because SOCs are consuming power.

Step $2\left(t_{1}-t_{2}\right)$ : Before switching the operating mode, current reference decreases to zero with a certain slope to prevent any over-voltages on the SOEC/SOFC stacks. At the end of this period, voltage across the SOEC/SOFC stacks reaches the open-circuit voltage.

Step $3\left(t_{3}\right)$ : The SPDT relays are switched, and the system connection is changed to SOFC mode as shown in Fig. 4a. A step variation of $V_{\text {conv }}$ occurs since the input voltage condition changes from Eq. 4 to Eq. 1.

Step $4\left(t_{3}-t_{4}\right)$ : Due to the $V_{\text {conv }}$ step variation, voltage oscillations occur across SOEC/SOFC stacks and $V_{\text {conv }}$. A short period of time with zero current is held to stabilize the system.

Step $5\left(t_{4}-t_{5}\right)$ : Current reference is driven with a certain slope to the maximum SOFC current capability $I_{\text {sof }, \text { max }}=$ $30 \mathrm{~A}$.

Step $6\left(t_{5}-\right.$ end $)$ : Systems is in steady state, operating in SOFC mode, where $V_{\text {conv }}=V_{\text {sofc }}$ and $P_{c o n v}=P_{\text {sofc }}$, as expressed with Eq. 1 and Eq. 3, respectively.

\section{DC-DC CONVERTER}

The main focus of this paper is the verification of the feasibility of the proposed PCU, for that reason a tailored dcdc converter with a closed-loop control has been implemented for the defined SOEC/SOFC system in table II.

\section{A. Power stage}

A three-stages Interleaved Boost Converter (IBC) is used in this work as shown in Fig. 7 to test the proposed PCU architecture. The IBC topology is a widely accepted topology for fuel cell power conditioning systems due to its benefits [17]-[20]. SOCs lifetime can be dramatically reduced with large ripple current [21], thus by means of interleaving the inductor currents, the input current ripple amplitude can be reduced [20], thus greatly improving the lifespan of SOCs. Moreover, the output voltage frequency is also increased, therefore reducing the voltage ripple and allowing a reduction of dc-link capacitors [20].

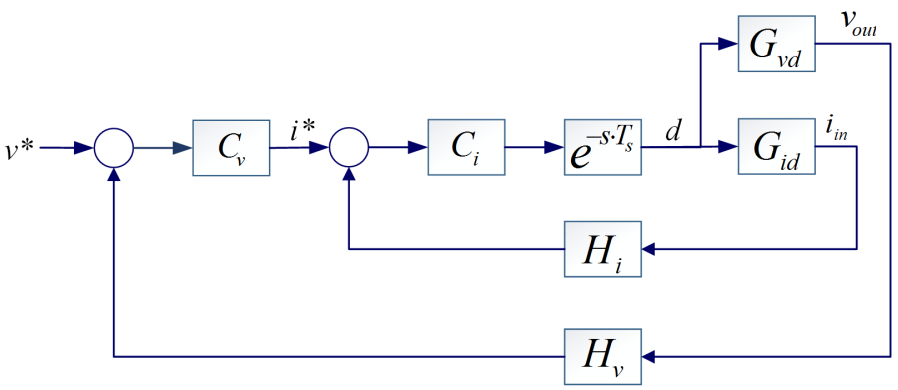

Fig. 8. Block diagram of the double-loop control strategy.

Converter's component details are given in Table III. Output voltage is set to $600 \mathrm{~V}$ in order to reach a proper dclink voltage level to feed energy to the grid and the switching frequency is $25 \mathrm{kHz}$.

TABLE III. CONVERTER'S COMPONENT DETAILS

\begin{tabular}{ll}
\hline \hline Inductors $L_{1}-L_{3}$ & $1 \mathrm{mH}$ KoolM $\mu$ core \\
DC-Link cap. (I) $C_{D C}$ & $20 \mu \mathrm{F} / 800 \mathrm{~V}$ Film Cap.: 2 in parallel \\
DC-Link cap. (II) $C_{D C}$ & $12 \mathrm{nF} / 800 \mathrm{~V}$ Film Cap.: 3 in parallel \\
Input cap. $C_{i n}$ & $50 \mu \mathrm{F} / 800 \mathrm{~V}$ Film Cap. \\
IGBTs $Q_{1}-Q_{3}$ & IKW25N120H3 $1200 \mathrm{~V} / 25 \mathrm{~A}$ \\
Diodes $D_{1}-D_{3}$ & IDH08S120 $1200 \mathrm{~V} / 7.5 \mathrm{~A}$ \\
\hline \hline
\end{tabular}

\section{B. Closed-loop control strategy}

A DSP-based closed-loop control system has been implemented. It is intended to design and apply the established control loop strategy for both operating modes (SOEC and SOFC) by considering the input-output I-V characteristics of the dc-dc converter in the design process.

The closed-loop control strategy is designed in order to reach and keep the $600 \mathrm{~V}$ output voltage and to keep the input power of the dc-dc converter inside the allowed limits of the SOC stacks.

The classical double-loop control strategy represented in Fig. 8 is applied [22], where $G_{i d}$ refers to the duty cycle-toinput current transfer function and $G_{v d}$ refers to the duty cycleto-output voltage transfer function. This controller requires the measurement of two variables, i.e. the dc output voltage and current at the input of the converter, which are filtered by second-order filters from the measurement circuits, $H_{i}$ and $H_{v}$, such that the high frequency components are properly attenuated. Classical proportional-integral (PI) controllers $C_{v}$ and $C_{i}$ are used for voltage and current compensation. In addition, a soft start-up procedure has been integrated to the control system, so during the converter turn-on voltage overshoots are avoided. The soft start-up consists of a reference signal $v_{r e f}$ with a certain slope from 0 to the desired reference.

Referring to the double-loop control, the fast inner loop is used to regulate the average input current using the controller $C_{i}$. The output voltage is regulated with the slower outer loop with the controller $C_{v}$. To obtain the closed-loop system stability, the inner loop bandwidth has to be larger than the outer loop [22]. Due to the slow dynamics of the SOCs the 


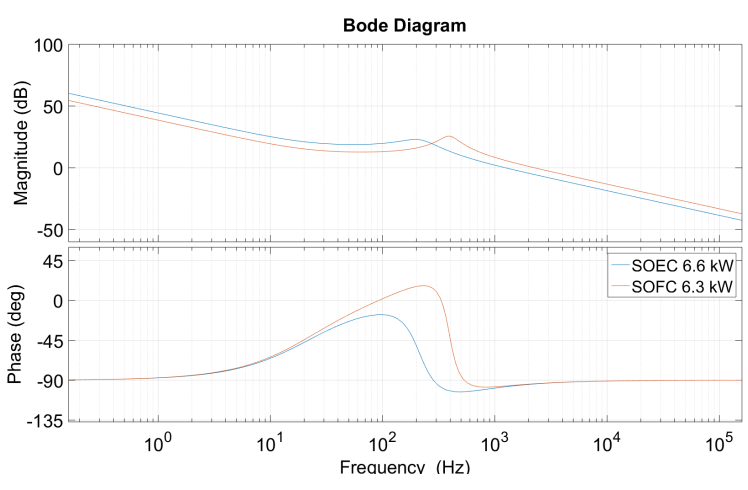

(a) Current loop gain.

Fig. 9. Control system Bode Plots

outer loop bandwidth has to be kept small and the inner current loop needs to assure reaching the faster transient response of the $\mathrm{dc}-\mathrm{dc}$ converter.

State-space average model for the IBC is developed as performed in [23], [24], to thereafter calculate the system transfer functions shown in Eq. 8 and Eq. 9.

$$
\begin{gathered}
G_{i d}=\left.\frac{\tilde{i}_{i n}(s)}{\tilde{d}(s)}\right|_{\tilde{v}_{\text {conv }}(s)=0}=\frac{V_{\text {conv }}}{R \cdot D^{\prime 2}} \cdot \frac{1+s \frac{1}{R \cdot C_{d c}}}{1+s \frac{L}{R \cdot D^{\prime 2}}+s^{2} \frac{L \cdot C_{d c}}{D^{\prime}}}(8) \\
G_{v d}=\left.\frac{\tilde{v}_{c}(s)}{\tilde{d}(s)}\right|_{\tilde{v}_{c o n v}(s)=0}=\frac{V_{c o n v}}{D^{\prime}} \cdot \frac{1-s \frac{L}{R \cdot D^{\prime 2}}}{1+s \frac{L}{R \cdot D^{\prime 2}}+s^{2} \frac{L \cdot C_{d c}}{D^{\prime}}}
\end{gathered}
$$

Where $D^{\prime}=1-D, R=V_{\text {out }} / I_{\text {out }}$ and $L=L_{1}=L_{2}=L_{3}$.

PI controller for inner current loop is designed for full load condition obtaining the bode diagram shown in Fig. 9a. The loop is closed at the cross-over frequency $f_{c}=1.25 \mathrm{kHz}$ with a phase margin of $83^{\circ}$ for the SOEC mode at full load and at $f_{c}=2.26 \mathrm{kHz}$ with a phase margin of $86^{\circ}$ for the SOFC mode on full load condition. Once the stability of the inner current loop is obtained, the outer voltage loop controller is calculated for full load condition and the closed-loop response shown in Fig. 9b is obtained.

\section{EXPERIMENTAL RESULTS}

Experimental tests have been carried out independently for each operating mode. Tests under SOFC mode have been executed simply using a laboratory power supply at the dcdc converter input and an output resistive load emulating the power demand from the dc-link side. Tests under SOEC mode have been carried out using a dc source to supply the ac-dc converter output voltage and an electronic load in fixed voltage mode with a dynamic resistance emulating the SOEC stacks power consumption. Fig. 10 shows the diagrams representing the experimental set-up.

Interleaved inductor currents and input current waveforms are shown in Fig. 11. From these results it is verified that the input current ripple is greatly reduced with the interleaving technique, therefore demonstrating an attractive topology for RFC systems.

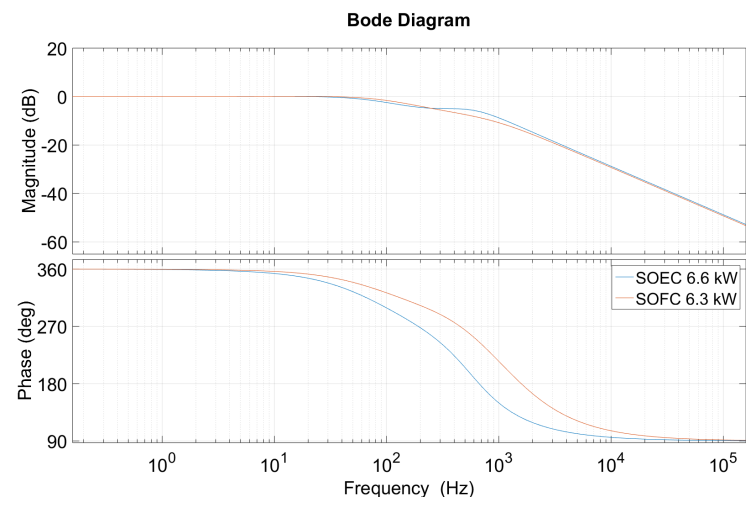

(b) Closed-loop response

\section{A. Efficiency measurements}

Efficiencies of the dc-dc converter are measured by using a power analyser PPA5530 from N4L. The efficiencies have been measured under SOEC and SOFC operating modes independently according to dc-dc converter I-P and I-V characteristics derived from the SOEC/SOFC stacks characteristics from Fig. 2. The results are shown in Fig. 12, clearly demonstrating that since the dc-dc converter can be rated for a similar power level in both operation modes, high efficiencies in both modes are possible. Note that efficiency curves are close to each other resulting in similar thermal stress for both modes which can simplify the heat sink design.

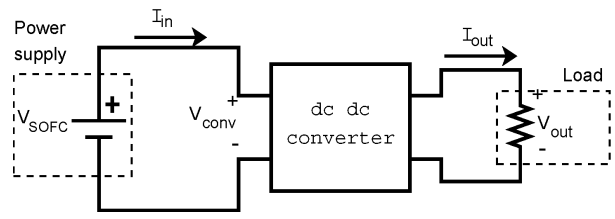

(a) SOFC tests

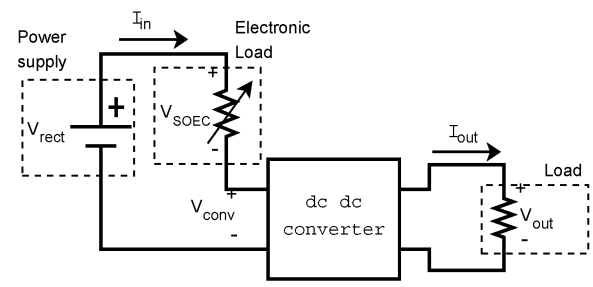

(b) SOEC tests

Fig. 10. Experimental set-up

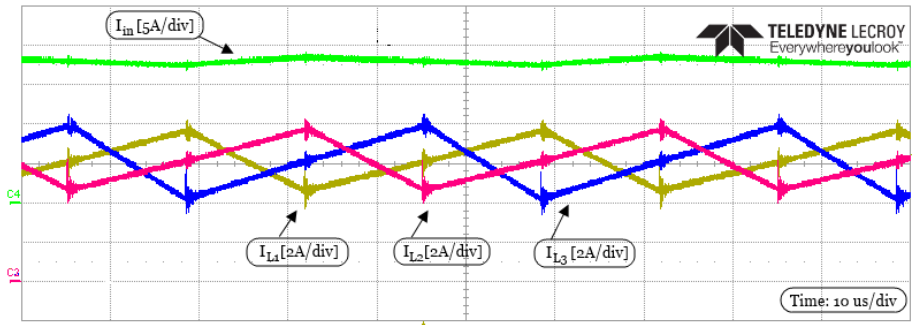

Fig. 11. Experimental results: 3 stages IBC inductors current $\left(I_{L 1}, I_{L 2}\right.$ and $I_{L 3}$ and input current $I_{i n}$. 


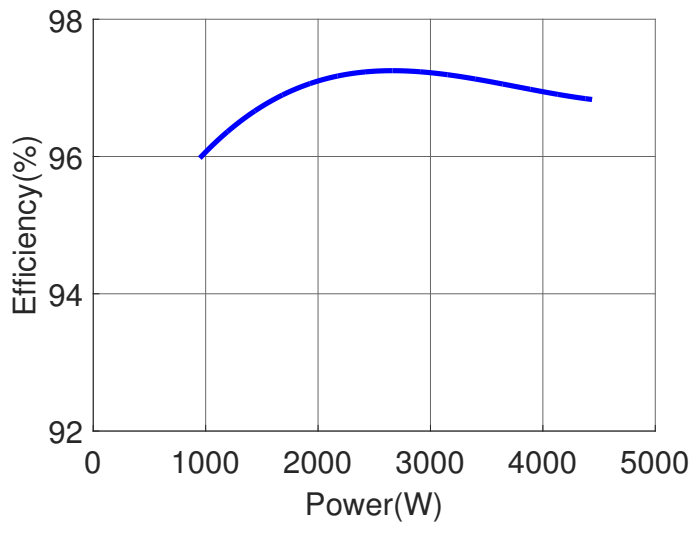

(a) SOFC mode

Fig. 12. Experimental and theoretical efficiency curves

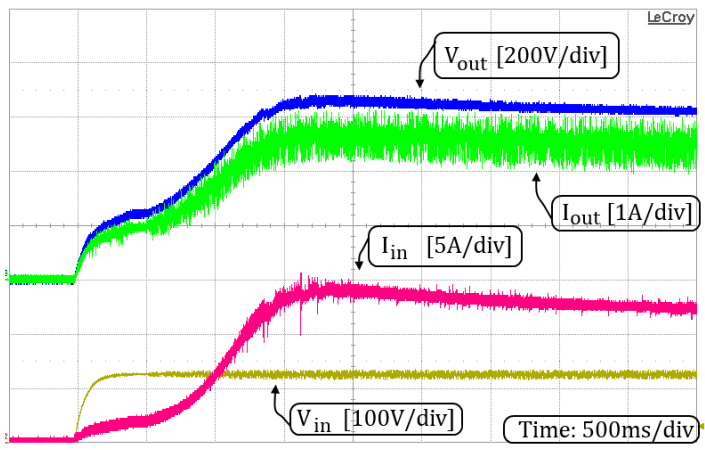

Fig. 13. Soft start-up test

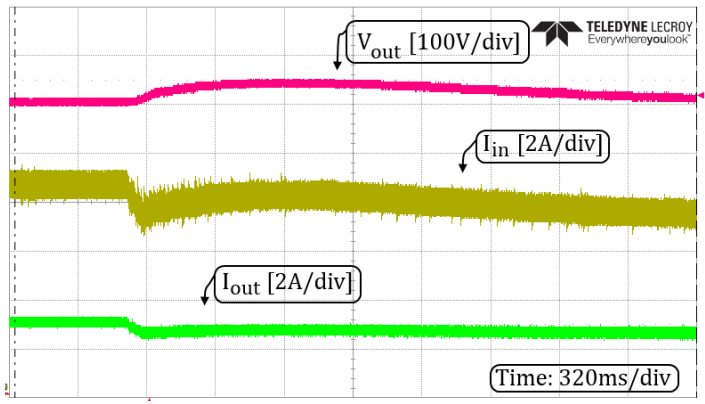

Fig. 14. $10 \%$ load step-up

\section{B. Closed-loop tests}

To verify the proposed PCU including its control design is suitable for both operating modes, closed-loop measurements are performed.

Fig. 13 shows the main converter waveforms during the system turn-on when a step from $0-120 \mathrm{~V}$ occurs at the input voltage. Steady-state condition is reached in approximately $4 \mathrm{~s}$, with a very smooth output voltage response having a small overshoot of $20 \mathrm{~V}$. Fig. 14 shows the system response for an output load step of $10 \%$ of the rated load, where the output voltage and input current have no oscillations and a small undershoot is appreciated. Fig. 15 shows the system response for SOFC voltage $\left(V_{i n}\right) 80 \mathrm{~V}$ step-up, where the inner

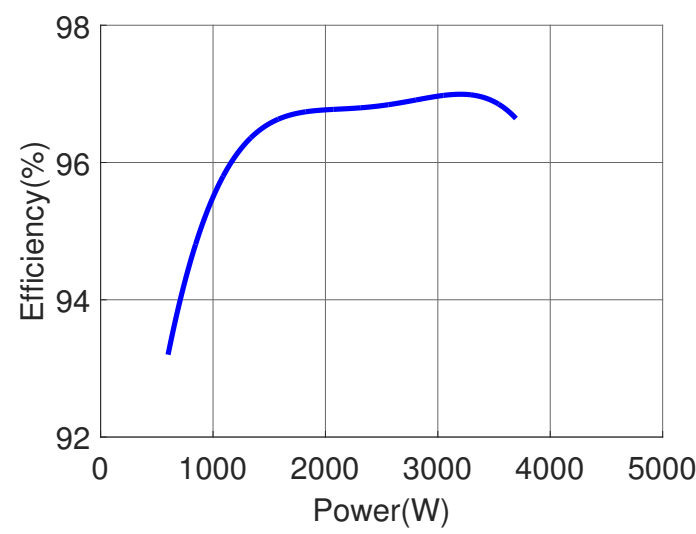

(b) SOEC mode

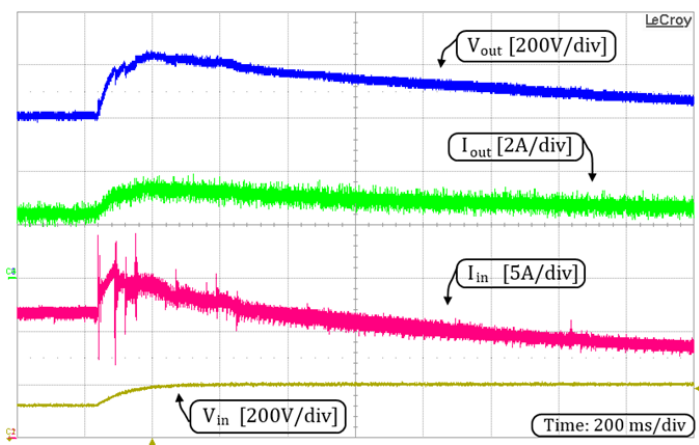

Fig. 15. SOFC voltage $80 \mathrm{~V}$ step-up

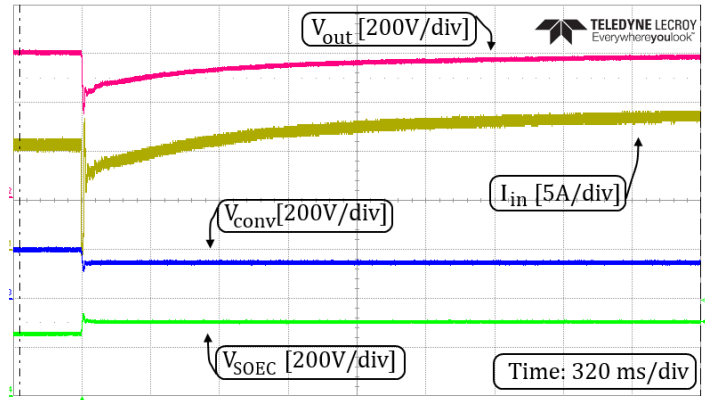

Fig. 16. SOEC voltage $50 \mathrm{~V}$ step-up

current loop suffers oscillations but the outer voltage loop has negligible oscillations and in $2 \mathrm{~s}$ steady-state is reached. Fig. 16 shows the system response for SOEC voltage $50 \mathrm{~V}$ step-up. Notice that the inverter voltage has been limited to $450 \mathrm{~V}$ to protect the voltage supply from over rated current. Similarly as with the previous test, few oscillations in the current are present at the step time, but the output voltage has a smooth response without noticeable oscillations, and reaching a steady-state condition within $2.2 \mathrm{~s}$. As explained throughout the system operation principle and simulations, the inverter voltage is shared across the SOEC and the dc-dc converter, leading to a reduced power rating of the dc-dc converter. 


\section{CONCLUSION}

This paper has presented the design considerations for a novel PCU for grid-tie SOEC/SOFC system. A $6.7 \mathrm{~kW}$ dcdc converter has been implemented which aims to be able to regulate $27 \mathrm{~kW}-\mathrm{SOEC} / 6.3 \mathrm{~kW}$-SOFC stacks, with efficiencies of up to $97 \%$ in SOEC mode and $97.3 \%$ in SOFC mode. Furthermore, it has been verified that the power rating reduction of the dc-dc converter in SOEC mode leads to a more symmetrical I-P characteristic of dc-dc converter which eases the design for a high efficiency converter, leading to similar efficiency curves for both operation modes of the SOEC/SOFC system. This not only results in similar losses in both modes, but can also be beneficial in terms of simplified heat sink design of the dc-dc converter power stage. Closed-loop experimental tests show that with a dual-loop control strategy, system robustness in terms of steady-state and transient performance is reliable under both operating modes SOEC and SOFC at the same time. Thus, the proposed PCU architecture can be a very attractive alternative for high efficiency RFC systems.

\section{REFERENCES}

[1] Z.H. Rather, Z. Chen and P. Thgersen Challenges of Danish Power Systems and Their Possible Solutions, IEEE International Conference on Power System Technology (POWERCON), 2012

[2] Y. Xu and C. Singh Power System Reliability Impact of Energy Storage Integration With Intelligent Operation Strategy, IEEE Transactions on smart grid, VOL.5, NO.2, March 2014.

[3] B. Dollinger and K. Dietrich Storage Systems for Integrating Wind and Solar Energy in Spain, IEEE International Conference on Renewable Energy Research and Applications (ICRERA), October 2013.

[4] G.L. Soloveichik Regenerative Fuel Cells for Energy Storage, Proceeding of the IEEE, VOL.102, NO.6, June 2014.

[5] Y. Redissi, H. Er.rbib and C. Bouallou Storage and restoring the electricity of renewable energies by coupling with natural gas grid, IEEE Renewable and Sustainable Energy Conference (IRSEC), 2013 International.

[6] M. Nymand and M.A.E. Andersen High-Efficiency Isolated Boost DCDC Converter for High-Power Low-Voltage Fuel-Cell Applications, IEEE Transactions on industrial electronics, VOL.57, NO.2, February 2010.

[7] R. Pittini, A. Anthon, Z. Zhang and M.A.E. Andersen, Analysis and Comparison on a Grid-Tie Fuel Cell Energy Storage System Based on $\mathrm{Si}$ and SiC Power Devices., IEEE International Power Electronics and Applications Conference and Exposition (PEAC), 2014.

[8] F.Z. Peng, H. Li, G.J. Su and J.S. Lawler A New ZVS Bidirectional DCDC Converter for Fuel Cell and Battery Application., IEEE Transactions on power electronics, VOL. 19, NO. 1, January 2004.

[9] R. Pittini, Z. Zhang and M.A.E. Andersen, High Current Planar Magnetics for High Efficiency Bidirectional DC-DC Converters for Fuel Cell Applications., Twenty-Ninth Annual IEEE, Applied Power Electronics Conference and Exposition (APEC), 2014

[10] M. Jang and V.G. Agelidis, Grid-Interfaced Fuel Cell Energy System Based on A Boost-Inverter with A Bi-Directional Back-Up Battery
Storage., IEEE Energy Conversion Congress and Exposition (ECCE), 2010

[11] A. Brisse,J. Schefold, C. Stoots and J.O'Brien Electrolysis Using Fuel Cell Technology, , In: W. Lehnert and R. Steinberger-Wilckens, Innovation in Fuel Cell Technologies, RSC Publishing, Cambridge, 263286, 2010

[12] G-B. Jung1, L.H. Fang, C.Y. Lin, X.V. Nguyen, C.C. Yeh, C.Y. Lee, J.W. Yu, S.H. Chan, W.T. Lee, S.W. Chang and I.C. Kao Electrochemical Performance and Long-Term Durability of a Reversible Solid Oxide Fuel Cell, International Journal of Electrochemical Science, 2015.

[13] A. Brisse,J. Schefold and G. Corre Performance and lifetime of Solid Oxide Electrolyzer Cells and Stacks, July 2015.

[14] Z. Zhang, R. Pittini, M.A.E. Andersen and O.C.Thomsen, A review and design of power electronics converters for fuel cell hybrid system applications. Renewable Energy Research Conference (RERC 2012), Technoport 2012.

[15] H. Qi, Y. Wu and Y. Bi, The Main Parameters Design Based On Threephase Voltage Source PWM Rectifier of Voltage Oriented Control., International Conference on Information Science, Electronics and Electrical Engineering (ISEEE), April 2014.

[16] Z. Zhang, R. Pittini, M.A.E. Andersen and O.C. Thomsen, A Review and Design of Power Electronics Converters for Fuel Cell Hybrid System Applications., Sharing Possibilities and 2nd Renewable Energy Research Conference (RERC2012), Technoport 2012

[17] J.E. Valdez-Resendiz, A. Claudio-Sanchez, G.V. Guerrero-Ramirez, C. Aguilar-Castillo, A. Tapia-Hernandez, J. Gordillo-Estrada, Interleaved High-Gain Boost Converter with Low Input-Current Ripple for Fuel Cell Electric Vehicle Applications., IEEE, International Conference on Connected Vehicles and Expo (ICCVE), 2013.

[18] O. Hegazy, J.V. Mierlo and P. Lataire, Analysis, Modeling, and Implementation of a Multidevice Interleaved DC/DC Converter for Fuel Cell Hybrid Electric Vehicles., IEEE, Transaction on power electronics, Vol. 27, No. 11, November 2012.

[19] K. Senthilkumar, M.S.K. Reddy, D. Elangovan and R. Saravanakumar Interleaved isolated boost converter as a front-end converter for fuel cell applications., IEEE, International Conference on Electrical Energy Systems (ICEES), January 2014.

[20] B.A. Miwa, D.M. Otten and M.F. Schlecht, High efficiency power factor correction using interleaving techniques., IEEE, Applied Power Electronics Conference and Exposition (APEC), 1992.

[21] G. Fontes, C. Turpin, R. Saisset, T. Meynard and S. Astier, Interactions between fuel cells and power converters: Influence of current harmonics on a fuel cell stack., 1 IEEE Power Electronics Specialists Conference, June 2004.

[22] O. Ellabban, O. Hegazy, J. Van Mierlo, P. Lataire, Dual loop digital control design and implementation of a DSP based high power boost converter in fuel cell electric vehicle., 12th International Conference on Optimization of Electrical and Electronic Equipment (OPTIM), 2010.

[23] H. Xu, E. Qiao, X. Guo, X. Wen and L. Kong Analysis and Design of High Power Interleaved Boost Converters for Fuel Cell Distributed Generation System., IEEE, Power Electronics Specialists Conference, June 2005.

[24] B. Bryant and M.K. Kazimierczuk Small-signal duty cycle to inductor current transfer function for boost PMM DC-DC converter in continuous conduction mode., Proceedings of the International Symposium on Circuits and Systems, May 2004. 